\title{
A Novel Mutation in the AVPR2 Gene in a Palestinian Family with Nephrogenic Diabetes Insipidus
}

\author{
Abdulsalam Abu-Libdeh ${ }^{1} \quad$ Isaiah D. Wexler ${ }^{2} \quad$ Imad Dweikat $^{1}$ David Zangen ${ }^{2}$ Bassam Abu-Libdeh ${ }^{1}$ \\ ${ }^{1}$ Department of Pediatrics, Makassed Islamic Hospital, \\ Jerusalem, Israel \\ 2 Department of Pediatrics, Hadassah University Hospital, \\ Jerusalem, Israel \\ Address for correspondence Abdulsalam Abu-Libdeh, MD, \\ Department of Pediatrics, Makassed Islamic Hospital, P.O.B. 19482, \\ Mount of Olives, Jerusalem, Israel \\ (e-mail: abdulsalam@hadassah.org.il).
}

J Child Sci 2017;7:e1-e3.

\begin{abstract}
Keywords

- nephrogenic diabetes insipidus

- AVPR2

- hypernatremia

- vasopressin

- vasopressin receptor

Nephrogenic diabetes insipidus (NDI) is a urinary concentrating defect resulting from resistance of the collecting duct to the antidiuretic action of vasopressin (AVP). The $\mathrm{X}$-linked recessive form is the most frequent genetic cause of inherited NDI and can be caused by mutations in the gene encoding the V2 vasopressin receptor (AVPR2). A Palestinian male infant presented in the neonatal period with failure to thrive, vomiting, irritability, fever, and polyuria, and had biochemical findings consistent with NDI. The diagnosis of NDI was established based on the clinical picture, absent response to desmopressin, and a similarly affected elder brother. Sequencing of the AVPR2 gene for the patient and his affected brother revealed a novel missense mutation with replacement of $G$ by $A$ in codon 82 located in exon 2 (TGC $\rightarrow$ TAC), causing a cysteine to tyrosine substitution (C82Y). Testing of the mother showed that she was the carrier of that mutation. This is the identified AVPR2 mutation in a Palestinian family. Knowledge of these mutations will allow genetic counseling and early diagnosis of affected males.
\end{abstract}

\section{Introduction}

Nephrogenic diabetes insipidus (NDI) is a clinical disorder characterized by a urinary concentrating defect resulting from resistance of the collecting duct to the antidiuretic action of vasopressin (AVP). X-linked NDI is the most common inherited form of NDI and is caused by mutations in the gene encoding the V2 vasopressin receptor $(V 2 R))^{1,2}$ Mutations of AVPR 2 are implicated in nearly $90 \%$ of all cases of congenital $\mathrm{NDI}^{3}$

Affected males with X-linked NDI develop a renal concentrating defect which is unresponsive to desmopressin administration. These affected individuals usually present with symptoms of dehydration, hypernatremia, renal insufficiency, mental retardation, and failure to thrive (FTT).
Heterozygous females exhibit variable degrees of polyuria and polydipsia due to skewed X-chromosome inactivation. ${ }^{4}$

Early recognition and treatment allow having a normal lifespan with appropriate physical and mental development. ${ }^{5}$ To date, 280 different mutations in the AVPR2 gene have been identified for V2R NDI, and the mutations spread throughout all portions of the protein. ${ }^{6}$

\section{Case Report}

A 2-month-old, $3.6 \mathrm{~kg}$ male infant, was born to nonconsanguineous Palestinian parents in good health. The family history was notable for an elder brother having evidence of NDI based on clinical description by the parents but unfortunately he was not diagnosed previously or adequately received

March 26, 2017

accepted

April 29, 2017
DOI https://doi.org/

10.1055/s-0037-1603743. ISSN 2474-5871.
Copyright (c) 2017 Georg Thieme

Verlag KG Stuttgart · New York
License terms

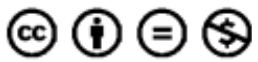


treated because referral to our tertiary center was not made by the treating physician in that area. Over a period of a month, the infant displayed increasing irritability associated with vomiting and FTT. The child was hospitalized, and was found to be cachetic and irritable. Weight, height, and head circumference were all below the third percentile. Laboratory evaluation revealed hypernatremia (sodium $150 \mathrm{mmol} / \mathrm{L}$ ), a serum osmolarity of $304 \mathrm{mOSm} / \mathrm{L}$, and urine osmolality of $145 \mathrm{mOsm} / \mathrm{L}$, urine output $9 \mathrm{~mL} / \mathrm{kg} / \mathrm{h}$, and urine specific gravity 1.005 . A renal ultrasound was normal. To determine whether the child had central or nephrogenic DI, DDAVP $20 \mu \mathrm{g}$ was administered as a single dose followed by serial measurements of serum sodium, serum osmolality, and urine osmolality. No changes in these values were noted, and a presumptive diagnosis of NDI was made and the child was managed appropriately. His management included adequate fluid and nutritional therapy, advice for low-salt, low-protein diet, and pharmacological treatment with diuretics (hydrochlorothiazide $3-4 \mathrm{mg} / \mathrm{kg} / \mathrm{d}$ ) and nonsteroidal antiinflammatory drugs (indomethacin $2 \mathrm{mg} / \mathrm{kg} / \mathrm{d}$ ). The child was discharged home and continues to grow and develop as expected.

\section{Sequencing of the AVPR2 Gene}

Before genetic studies, an informed consent was obtained from the study participants or their guardians. The study was approved by the Institutional Review Boards of Makassed Islamic Hospital.

Automated DNA sequencing was performed using the BigDye terminator cycle sequencing chemistry from Applied Biosystems (ABI, Foster city, California, United States), the ABI PRISM 3700 DNA analyzer and ABI's data collection software. Results were analyzed with the sequence analysis software and compared with the sequence available from the National Center for Biotechnology Information (NCBI) database (340298).

\section{Results}

Sequencing the coding region of the AVPR2 gene of the affected patient showed hemizygous missense $G$ to A mutation at nucleotide 606 in codon 82 (TGC $\rightarrow$ TAC) (numbering based on AVPR2 sequence in GenBank-accessionnumber L22266). This mutation results in a substitution of tyrosine for cysteine (C82Y) in exon 2 located in transmembrane domain II (-Fig. 1). The same mutation was found in the affected brother. No other mutations were found in the coding sequence of AVPR2. The mother and sister were heterozygous for this mutation while the father and unaffected brother did not have the mutation (-Fig. 1 ).

\section{Discussion}

NDI is a rare disease which is caused by mutations of the V2R. AVPR2 belongs to the subfamily of G-protein coupled receptors with seven transmembrane domains. ${ }^{7}$ AVPR2 is a polypeptide of 371 amino acids and mediates the AVP.

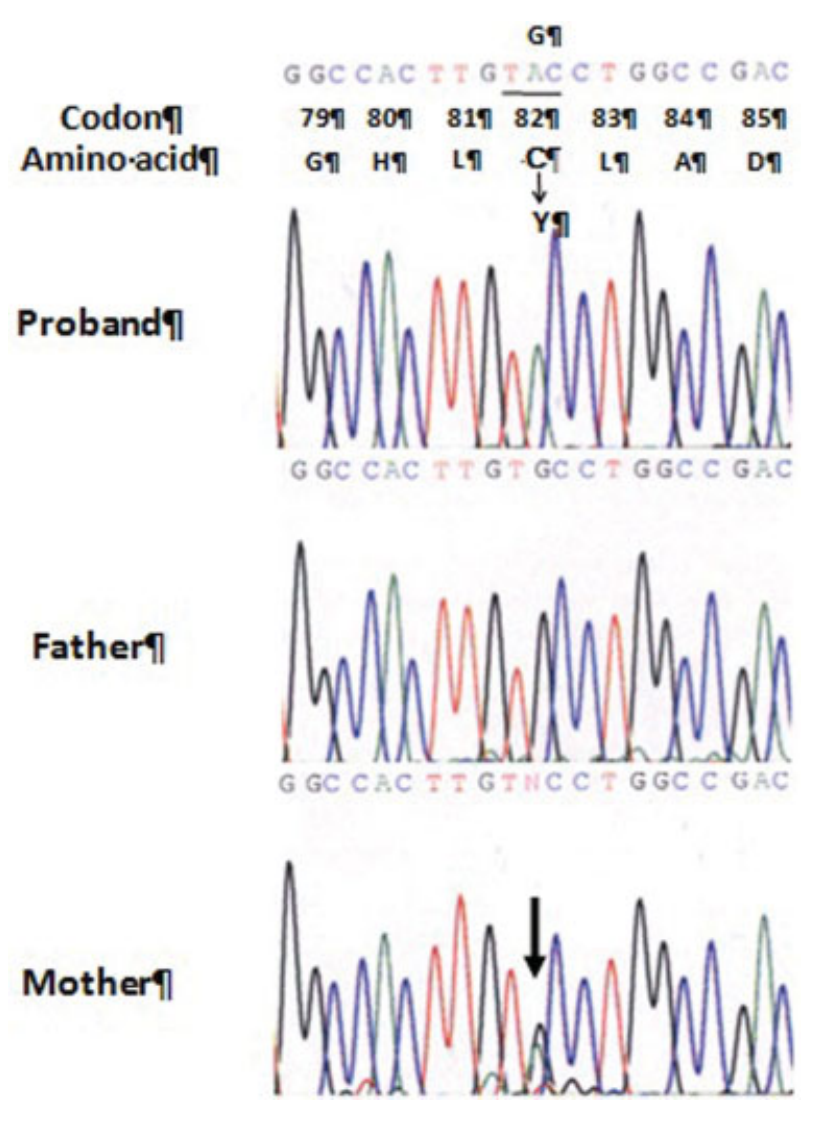

Fig. 1 Mutational analysis of the proband, father, and mother. A missense $G$ to $A$ mutation at nucleotide 606 (thin arrow) in codon 82 results in a substitution of tyrosine for cysteine (C82Y). Note the double band at this site (thick arrow) in the mother's sequence indicating that she is heterozygous for the mutation.

NDI usually presents with polyuria, polydipsia, volume depletion, hypernatremia, hyperthermia, irritability, constipation, FTT, developmental delay, and mental retardation, decreased appetite and poor food intake due to consumption of large amount of water, growth abnormalities, and behavioral problems including hyperactivity.

The high urine flow associated with NDI may complicate to hydronephrosis and may progress to loss of renal function and possible end-stage renal disease.

The missense mutation identified in our patient induced a (C82Y) amino acid substitution. This mutation is located in the transcellular domain II of the gene. Based on the database of human AVPR2 mutations (available at: http:// www.medicine.mcgill.ca/nephros), this would appear to be a new mutation. ${ }^{8}$ This is a region with a predilection to mutations as there have been numerous reports of mutations in this domain including missense and deletion mutations involving amino acids $80,81,83,84,85$, and 88 (see - Fig. 1). No functional studies were performed and we considered the amino acid change in the gene as pathogenic (i.e., mutation) based on the following: positive segregation in the family (heterozygous mother and healthy sister, hemizygous mutated in the affected boys, hemizygous normal father, 
and unaffected brother, the amino acid change is in a region with a predilection to mutation (as stated above), the changed amino acid is in a conserved residue. All of the reported mutations have been associated with clinical disease. D85 is a highly conserved residue which has a role in receptor activation in many G-protein-coupled receptors. ${ }^{9}$ Albertazzi et al showed in functional studies that A84 is important for both protein sorting to the plasma membrane and reduced receptor affinity. ${ }^{10}$ It is likely that our mutation, similar to the other nonconservative mutations in this segment affect protein folding thereby affecting protein trafficking and the protein's affinity for its ligand.

Although congenital NDI is rare, it is important to identify it very early in life to prevent hypernatremia, dehydration, and their associated consequences. Early intervention with fluid therapy, a decreased solute diet and administration of pharmacologic therapies such as diuretics (hydrochlorothiazide) and nonsteroidal anti-inflammatory drugs (indomethacin) are effective therapies and can prevent the development of hydronephrosis. All measures are in parallel with providing adequate nutrition by providing appropriate amount of calories and special nutrients to try correct the associated FTT. Knowledge of the mutation allows for genetic counseling.

\section{References}

1 van den Ouweland AM, Dreesen JC, Verdijk M, et al. Mutations in the vasopressin type 2 receptor gene (AVPR2) associated with nephrogenic diabetes insipidus. Nat Genet 1992;2(02):99-102

2 Rosenthal W, Seibold A, Antaramian A, et al. Molecular identification of the gene responsible for congenital nephrogenic diabetes insipidus. Nature 1992;359(6392):233-235

3 Morello JP, Bichet DG. Nephrogenic diabetes insipidus. Annu Rev Physiol 2001;63:607-630

4 Arthus MF, Lonergan M, Crumley MJ, et al. Report of 33 novel AVPR2 mutations and analysis of 117 families with X-linked nephrogenic diabetes insipidus. J Am Soc Nephrol 2000;11(06):1044-1054

5 Fujiwara TM, Morgan K, Bichet DG. Molecular biology of diabetes insipidus. Annu Rev Med 1995;46:331-343

6 Stenson PD, Ball EV, Mort M, et al. Human Gene Mutation Database (HGMD): 2003 update. Hum Mutat 2003;21(06):577-581

7 Birnbaumer M, Seibold A, Gilbert S, et al. Molecular cloning of the receptor for human antidiuretic hormone. Nature 1992; 357(6376):333-335

8 Spanakis E, Milord E, Gragnoli C. AVPR2 variants and mutations in nephrogenic diabetes insipidus: review and missense mutation significance. J Cell Physiol 2008;217(03):605-617

9 Wess J. G-protein-coupled receptors: molecular mechanisms involved in receptor activation and selectivity of G-protein recognition. FASEB J 1997;11(05):346-354

10 Albertazzi E, Zanchetta D, Barbier P, et al. Nephrogenic diabetes insipidus: functional analysis of new AVPR2 mutations identified in Italian families. J Am Soc Nephrol 2000;11(06):1033-1043 